\title{
FLICKER FUSION CHARACTERISTICS OF ROD PHOTORECEPTORS IN THE TOAD
}

\author{
Linda M. Nowak and Daniel G. Green* \\ Neuroscience Laboratory, University of Michigan, Ann Arbor, MI 48109, U.S.A.
}

(Received 22 September 1982; in revised form 28 December 1982)

\begin{abstract}
Critical fusion frequency (CFF) of toad rods was examined at various intensities using intracellular recordings. Data were compared to CFF measurements (as a function of intensity) obtained with the electroretinogram (ERG) and with a horizontal cell. In all instances the rod (and rod mediated) responses produced a curve which increased monotonically to a high frequency asymptote at about $6 \mathrm{~Hz}$. The curves obtained with the ERG and the horizontal cell were double branched. The upper branch exhibited a Purkinje shift and thus must have been produced by cones. Even when using a red background to suppress cone sensitivity, there was no sign of a second rod mediated branch in the CFF curves from this retina.
\end{abstract}

\section{INTRODUCTION}

The critical fusion frequency (CFF) is the rate at which a light presented repetitively ceases to evoke flickering responses. In general, the more intense the stimulus the higher the CFF. When CFF is plotted against stimulus intensity it frequently is a curve with two separate smooth branches. This traditionally is an indication of the presence of both rods and cones. At low intensities responses are mediated by the rods; while rods are very sensitive, they are slow and consequently the CFF is low. As stimulus intensity is increased, a point is reached where responses begin to be mediated by cones and the CFF rises sharply (Hecht, 1937; Walls, 1942).

A kink in the CFF intensity curve need not imply cone mediated responses. Green and Siegel (1975) working on the eye of the common skate, an elasmobranch with an all rod retina, found double branched CFF curves when recording electroretinograms, S-potentials and massed receptor potentials. Two years later a psychophysical study in man demonstrated a similar double branched relationship for human rods (Conner and MacLeod, 1977). In both studies, spectral sensitivity determinations showed that the receptors producing the two branches contained the same rod pigment. Unanswered, however, was the question of whether the ability to follow rapid flicker is a property of all the rods in these retinas or represents the responses of a subset of less sensitive rods with unusually rapid kinetics.

One obvious way to determine what happens is to record from individual rods. For technical reasons it has not been possible to obtain stable intracellular recordings from skate rods. Consequently, we have recorded from Bufo marinus rods. The rods of this animal are large and readily accessible to intracellular

*To whom reprint requests should be addressed. recording. Because toad rods, like skate rods, initially saturate and then recover sensitivity during prolonged bright light exposure (Fain, 1976), we anticipated finding two branched flicker curves. Despite this expectation, the studies we report here indicate that the rhodopsin rods of the marine toad form a single class of photoreceptors that do not dramatically change their response characteristics.

\section{METHODS}

The animals were placed in a brightly illuminated terrarium for $2-4 \mathrm{hr}$, then transferred to the dark for $30 \mathrm{~min}$ before pithed and having their eyes excised and hemisected under dim red light. The initial period of light adaptation helped to minimize the chances of retinal detachment. A portion of the vitreous was removed using absorbent paper wicks, the eye cup placed in a standard recording chamber through which moist $100 \% \mathrm{O}_{2}$ was gently blown and the eye cup dark adapted for an additional hour.

Uniform illumination of the eye cup was achieved through a conventional two channel photostimulator (Oakley and Green, 1976). The incident llux was measured in both beams at all wavelengths using a calibrated PIN-10 photodiode (United Detector Technology). To obtain the rate of photon absorption the measured flux at $500 \mathrm{~nm}$ was multiplied by $24 \mu \mathrm{m}^{2}$, the effective cross-sectional area of the rod obtained by taking rod cross-sectional area as $47 \mu \mathrm{m}^{2}$, mean absorption as $77 \%$ and quantum efficiency of bleaching as 0.67 (Fain, 1975). Squarewave flickering stimuli were produced using a rotating sectored disk. The retina was allowed to adapt for 5-7 min at each stimulus intensity. Follouing this, critical fusion frequency (CFF) was determined by increasing the frequency of stimulation until the response disappeared in the base-line noise of the recording $(0.5 \mathrm{mV}$ peak-to-peak for intracellular 
recordings and $10 \mu \mathrm{V}$ peak-to-peak for electroretınogram recordings: ERGs). Stımulus intensits was increased stepwise and CFF data recorded at each intensity. In some ERG expenments, a steady red background $(650 \mathrm{~nm} .50 \mathrm{~nm}$ half bandwidth or $625 \mathrm{~nm} ; 10 \mathrm{~nm}$ half bandwidth interferance fitters) superimposed upon the fickenng stimulı was used to preferentially adapt cones. $B$-wave responses to dim, brief. flashed 500 and $600 \mathrm{~nm}$ stimuli were scotopically equated in the presence of a dim red background. The ratio of the steady red background intensity to the scotopically equated flickering test $(500$ and $600 \mathrm{~nm})$ intensity was kept constant. That is, each time test intensity was increased background intensity was increased by the same factor.

Intracellulat recordings were made with high resistance (150-300 M $\Omega$ ) glass micropipettes (Omega Dot) filled with $2 \mathrm{M}$ potassium acetate. Rhodopsincontaining rods were distunguished from other cells by retinal depth of recording, by the characteristic shapes of responses to brief $(100 \mathrm{msec})$ flashes and by using scotopically equated 500 and $600 \mathrm{~nm}$ stimuli. Rhodopsin rods responded identically to scotopically equated stimuli at both low and high intensities while horizontal cells responded to bright stimuli with smaller responses to 500 than to $600 \mathrm{~nm}$. The reverse was true for the one short wavelength ("green") rod we encountered (i.e. it responded better to 500 than $600 \mathrm{~nm}$ stimuli). Complete spectral sensitivity curves were obtaned from several rhodopsin containing rods. In each case these curves peaked at $500 \mathrm{~nm}$ and confirmed the identification made on the basis of the two point $(500-600 \mathrm{~nm})$ spectral sensitivity test. Dark adapted rods responded equally to dim brief $500 \mathrm{~nm}$ and white light stimuli if $1.5 \mathrm{log}$ neutral density was added to the white stimulus.

The vitreal electroretinogram (ERG) was monitored to assess the physiological condition of the retina during intracellular recording and to investigate the CFF function of the ERG $h$-wave. Recordings were made with blunt, low resistance (about $5 \mathrm{M} \Omega$ ) Ringer-agar pipettes. The $b$-wave intensity response function was measured with maximum $b$-waves ranging from 310 to $790 \mu \mathrm{V}$.

\section{RESULTS}

\section{Rod intracellular recordings}

Intracellular recordings were made from 44 cells identified as rhodopsin rods. Critical fusion frequency measurements were made from a total of 7 rods which responded to brief bright stimuli with $15 \mathrm{mV}$ or greater hyperpolarization and which were held long enough to make flicker measurements at two or more intensities ( $30 \mathrm{~min}$ or longer). Two different stimulus conditions were used. Data were obtained with white light flicker from 4 rods (Fig. I: solid symbols) over $7 \mathrm{log}$ units of intensity. Similar measurements were made with $500 \mathrm{~nm}$ stimuli from 3 other rods (Fig. 1: open symbols). Both stimulus

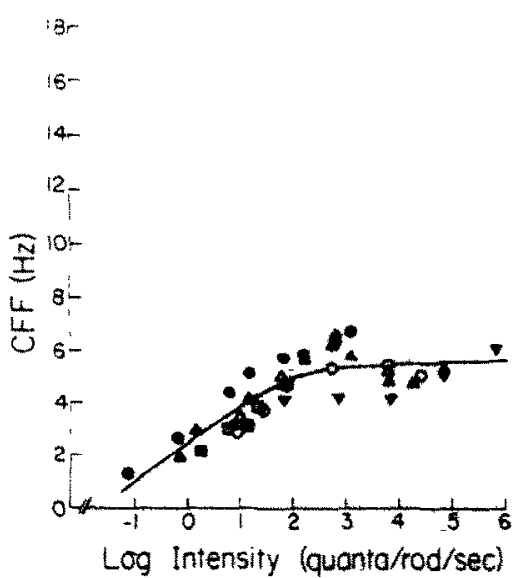

Fig. 1. Cntical fusion frequency (CFF) vs stumulus intensity for thodopsin rod photoreceptors. Each symbol represents the CFF response of a single rod to on-off fickering stimuti at 2 or more light intensities. Sold symbols indicate white light data and open symbols represent $500 \mathrm{~nm}$ ficker. CFF data obtained with white light stimuli are plotted against the effective $300 \mathrm{~nm}$ quantal absorbance of the thodopsin rod photoreceptors (see text for details)

conditions yielded the same result. Critical ficker frequency in rhodopsin-containing rods was a monotonically increasing function of light intensity. Maximum CFF ranged from 4.2 to $6.7 \mathrm{~Hz}$ for individual rods.

\section{Horizontal cell recordings}

Intracellular recordings were made from 7 identified horizontal cells and CFF data were obtained from one horizontal cell (Fig. 2). Over the same range of intensities used with the rods, critical flicker fusion (CFF) was a two branched function. An

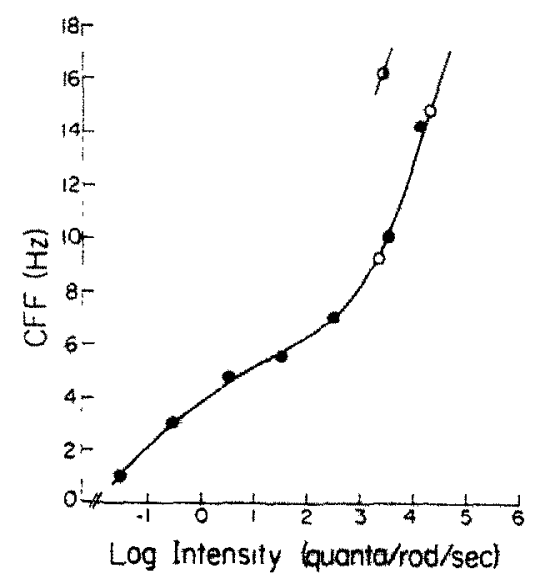

Fig. 2. Critical fusion frequency (CFF) vs stimulus intonsity for a horizontal cell. Solid cindes indicate white light licker. open symbols represent CF responses to $500 \mathrm{nim}$ ficker and half filled symbol represents CFF respoinse to $600 \mathrm{~nm}$ stimuli. The 500 and $600 \mathrm{~mm}$ stimuli were $5 c 0$ topically equated using the dark-adapted ERG $h$-wave. CFF data obtained with white light ficker are expressed in terms of the effective quantal absorbance in the rods 


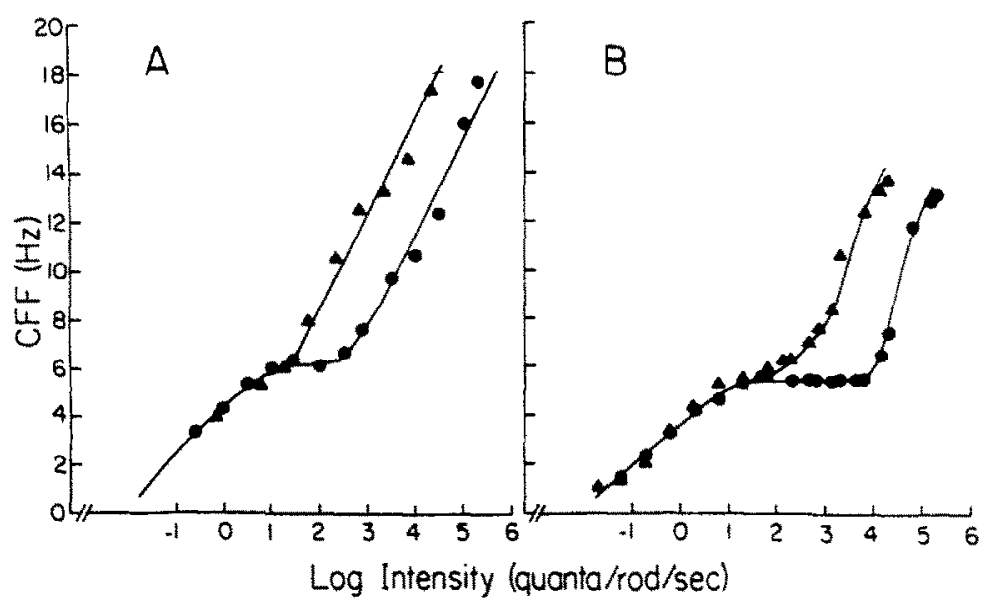

Fig. 3. Critical fusion frequency (CFF) vs stimulus intensity for the $b$-wave of the electroretinogram (ERG). (A) Dark Adapted: ERG frequency responses were measured as a function of light intensity using $500 \mathrm{~nm}$ (circles) and $600 \mathrm{~nm}$ (triangles) flickering stimuli against a dark background (DA). (B) Modulated Flicker: ERG frequency responses were measured as a function of light intensity using $500 \mathrm{~nm}$ (circles) and $600 \mathrm{~nm}$ (triangles) flickering stimuli in a fixed ratio to a red background $(625 \mathrm{~nm} ; 10 \mathrm{~nm}$ half band width). The ratio of test to background intensity in scotopic units was maintained at $2: 1$.

inflection in the horizontal cell CFF (Fig. 2: solid symbols) occurred at about $6.5 \mathrm{~Hz} \quad(100$ quanta/rod/sec) which corresponded to the plateau of CFFs obtained in individual rods. Increasing intensity above 1000 quanta/rod/sec yielded a dramatic increase in CFF. The maximum frequency obtained on the second branch was about $16 \mathrm{~Hz}$. Horizontal cells in toad receive information from both rods and cones (Fain, 1976). Consequently, the spectral sensitivity of this second branch of the CFF function was examined using scotopically equated 500 and $600 \mathrm{~nm}$ flickering stimuli (Fig. 2; open circles vs half-solid circle). These data made the cone influence in the second branch apparent. Where the horizontal cell responded to fast flicker it was approx. $1.0 \mathrm{log}$ unit more sensitive to 600 than to $500 \mathrm{~nm}$ stimuli. Thus, the intracellular data obtained from toad rods and horizontal cells were consistent with the classically held assumption that the rods respond to low frequency flickering lights and that cells which exhibit faster temporal properties receive cone input.

\section{ERG recordings}

The cells we have recorded from do not provide evidence for a fast ficker mechanism in rods. However, due to selection biases (see rod recordings) we might have missed a second class of rapidly responding rods. Consequently, we decided to conduct experiments using the electroretinogram (ERG) to establish whether a second, fast rod system might be uncovered.

CFF curves were obtained from ERGs recorded in 14 eyecups; 5 with no background (dark adapted), 5 with a fixed intensity long wavelength background (light adapted) and 4 with the background and test intensity in a fixed ratio (modulated flicker). Data from light adapted eyecups (LA) were intermediate between those obtained for dark adapted (DA) and eyecups presented with modulated fickering (MF) stimuli (see table). Figure 3A shows flicker data obtained with 500 and $600 \mathrm{~nm}$ on-off flickering stimuli from a dark adapted eyecup. These data should be compared with similar data obtained from modulated flicker (see Fig. 3B). In both conditions, the CFFintensity functions had two branches and the responses to high intensity rapid ficker exhibited a Purkinje shift of about $1.0 \mathrm{log}$ unit. Thus, the first branch reached a plateau at $6.0 \mathrm{~Hz}$ adapted and $5.5 \mathrm{~Hz}$ with modulated flicker. The only difference between the two conditions is that adding a red background in fixed ratio to the flickering stimulus, shifted the response of the cones to higher intensities. This extended the range of light intensities over which responses of the scotopic mechanism could be observed. With a $500 \mathrm{~nm}$ stimulus the data in Fig. 3B show that the scotopic branch of the ficker function was a monotonic function to $1 \times 10^{4}$ quanta/rod $/ \mathrm{sec}$, stimulation. For $500 \mathrm{~nm}$ stimuli the rod-cone break occurred at an intensity of $2.9 \mathrm{log}$ quanta/rod/sec in dark adapted eyecups and at a log unit higher intensity ( $3.9 \mathrm{log}$ quanta/rod/sec) in eyecups tested with modulated flicker (see table). In every case where a second CFF branch was present there was a Purkinje shift of from 1.0 to $1.5 \mathrm{log}$ units (see table). However, in one experiment (Experiment No. 13; table) no second branch was observed in the CFF function and at all intensities the spectral sensitivity was that of rods. Thus, the scotopic branch of the ERG flicker curve agreed with the results obtained from individual rods. The electroretinogram provided evidence for a second branch but in every instance it represented the cone activity. 


\begin{tabular}{|c|c|c|c|c|}
\hline Conditions & Experiment No & $\begin{array}{c}\text { Rod } \\
\text { platedu } \\
(\mathrm{Hz})\end{array}$ & $\begin{array}{c}\text { Purkinge } \\
\text { shitt } \\
\left(\log _{b 1}\right)\end{array}$ & $\begin{array}{l}\text { Rod-cone break } \\
(500) \mathrm{nm} \\
\text { flog quantal rou sec) }\end{array}$ \\
\hline \multirow{6}{*}{$\mathrm{DA}$} & $1^{*}$ & 65 & - & 2 \\
\hline & 2 & 75 & 14 & 27 \\
\hline & $3 *$ & +5 & -- & 35 \\
\hline & + & 60 & 14 & 27 \\
\hline & 5 & 50 & 12 & 28 \\
\hline & Mean values & 6.5 & 1.3 & 29 \\
\hline \multirow{6}{*}{ LA } & 6 & 6.0 & 12 & 35 \\
\hline & 7 & 9.0 & 10 & 2.7 \\
\hline & 8 & 4.3 & 1.0 & 2.9 \\
\hline & 9 & 60 & 1.1 & 2.8 \\
\hline & 10 & 5.0 & 1.0 & 3.1 \\
\hline & Mean values & 6.1 & 1.1 & 3.0 \\
\hline \multirow{5}{*}{ MF } & 11 & 5.5 & 1.1 & $3.8(3: 2)$ \\
\hline & 12 & 5.5 & 1.0 & $4.0(2: 1)$ \\
\hline & $13 t$ & 4.2 & - & $-(1: 1)$ \\
\hline & 14 & 5.0 & 1.5 & $3.8(1: 1)$ \\
\hline & Mean values & 5.1 & 1.2 & 3.9 \\
\hline
\end{tabular}

$\mathrm{DA}=$ dark adapted; $\mathrm{LA}=$ light adapted, $\mathrm{MF}=$ modulated flicker. For the MF condition the ratio of test intensity to background intensity for tods is shown in parentheses at the right. $625 \mathrm{~nm}$ (Experiment Nos. 11 and 12) and $650 \mathrm{~nm}$ (Experiment Nos. 13 and 14) backgrounds were used.

*White light flicker-values included in rod-cone break column were shifted (1.5 log quanta) to correspond to rod quantal absorbance for $500 \mathrm{~nm}$ flicker.

†No second branch was present.

\section{DISCUSSION}

We have been unable to demonstrate duplex flicker responses in toad rods. While this is essentially a negative finding, it does tell us important things about rod flicker. First, we now know that rods do not exhibit double branched flicker-intensity relationships in all eyes. Moreover, the fact that Bufo rods do not exhibit this property tends to exclude a number of processes that were candidates for producing double branched flicker.

Light adaptation shortens the duration of the rod response to brief flashes in toad (Bastian and Fain. 1979: Baylor et al., 1979), in skate (Dowling and Ripps, 1971) and in other cold blooded vertebrates (Baylor and Hodgkin, 1974; Hood and Grover, 1974; Detwiler, Hodgkin and McNaughton, 1980). The increased speed contributes to the higher CFF obtained with brighter stimuli (shown in Fig. 1), but it does not produce a kink in the flicker-intensity relationship (Toyoda and Coles, 1975).

The recent findings of faster responses at the basal end of the outer segment than at the distal tip of toad rods (Baylor et al., 1979) might-suggest that fast ficker responses are generated in the base and slow flicker responses in the apex of the outer segment. Our data from the toad indicates that such differences do not cause the rods to respond to fast flicker in the way they do in skate and man.
Green and Siegel reported that the abrupt increase in CFF was associated with saturation of the response amplitude. That is, it appeared only after the rods had been exposed to a steady light that had driven the response to its maximum limits. Such stimuli initially make skate rods unresponsive, but then they recover with time (Dowling and Ripps, 1970, 1971). After recovery, skate rods are capable of following high frequency flicker (Green and Siegel, 1975). This led the above authors to suggest that the two processes were related. That is, the same mechanism responsible for shifting the skate rod's response range might also enhance its temporat resolution. Toad rods have the ability to recover from saturating stimuli (Fain, 1976). Severat hundred quanta per sec produce maximum amplitude rod responses so that at the highest intensities shown in Fig. 1, the stimulus onset initially saturated the rod response- Recovery from saturation is not, however. accompanied by a dramatic increase in the rod"s ability to respond to high frequency ficker. Fast ficker responses in toad seem to be associated exclusively with cones.

Acknowledgements - This reseanch was supported in part by NIH grant EY00379. LMN was supported by NIMH training grant 14279 to the Neuroscience Program. Adrienne Graves and John McReynolds read an earlier version of the manuscript and offered helpful comments. 


\section{REFERENCES}

Bastian B. L. and Fain G. L. (1979) Light adaptation in toad rods: Requirement for an internal messenger which is not calcium. J. Physiol. 297, 493-520.

Baylor D. A. and Hodgkin A. L. (1974) Changes in time scale and sensitivity in turtie photoreceptors. J. Phisiol. 242, 729-758.

Baylor D. A., Lamb T. D. and Yau K. W. (1979) The membrane current of single rod outer segments. $J$. Phys iol. 288, 589-611.

Conner J. D. and MacLeod D. I. A. (1977) Rod photoreceptors detect rapid ficker. Science 195, 698-699.

Detwiler P. B., Hodgkin A. L. and McNaughton P. A. (1980) Temporal and spatial characteristics of the voltage response of rods in the retina of the snapping turtle. $J$. Physiol. 300, 213-250.

Dowling I. E. and Ripps H. (1970) Visual adaplation in the skate retina. $J$. gen. Physiol. 56, 459-474,

Dowling J. E. and Ripps $H$. (1971) S-potentials in the skate retina: Intracellular recordings during light and dark adaptation. J. gen. Physiol. 58, 163-189.
Fain G. L. (1975) Quantam sensitivity of rods in the toad retina: Science 187, 838-840.

Fain G. L. (1976) Sensitivity of toad rods: dependence on wave-length and background illumination. $J$. Phriol. 261, 71-101.

Green D. G. and Siegel I. M. (1975) Double branched flicker fusion curves for the all rod skate retina. Science 188 , $1120-1122$.

Hecht S. (1937) Rods, cones and the chemical basis of vision. Physiol. Rev. 17, 239-290.

Hood D. C. and Grover B. G. (1974) Temporal summation of light energy by a vertebrate visual receptor. Science 184, $1003-1005$.

Oakley B. and Green D. G. (1976) Correlation of lightinduced changes in retinal extracellular potassium concentration with c-wave of the electroretinogram. $J$. Neurophysiol. 39. 1117-1133.

Toyoda J. and Coles J. A. (1975) Rod response to sinusoidally flickering light. Vision Res. 15, 981-983.

Walls G. L. (1942) The Vertebrate Eye and its adaptive radiation. Cranbrook, Bloomfield Hills. 